\title{
PENGARUH PENGETAHUAN PERPAJAKAN DAN KUALITAS PELAYANAN PAJAK TERHADAP MOTIVASI DALAM MEMBAYAR PAJAK PENGHASILAN (STUDI PADA WPOP DI KEC. WANEA KOTA MANADO)
}

\author{
Polii Cimberly ${ }^{1}$, Hendrik Manossoh $^{2}$, Heince R.N. Wokas ${ }^{3}$ \\ ${ }^{1, F a k u l t a s ~ E k o n o m i ~ d a n ~ B i s n i s, ~ J u r u s a n ~ A k u n t a n s i, ~ U n i v e r s i t a s ~ S a m ~ R a t u l a n g i, ~ J l . K a m p u s ~ B a h u, ~ M a n a d o, ~}$ \\ 95115, Indonesia \\ E-mail : cimberly.nicole@yahoo.com
}

\begin{abstract}
This research aims to examine the effect of tax knowledge and the quality of tax service on motivation in paying income tax. The sample in this research are all individual taxpayers who reside in the district wanea of manado city. The data in this research is using primary data. It was collected by distributing questionnaires directly to individual taxpayers in the district wanea of manado city. The data taken was processed using the multiple linear regression analysis with the help of SPSS 23. The result indicate that: tax knowledge has positive effect towards motivation in paying income tax. The quality of tax service has positive effect towards motivation in paying income tax. Tax knowledge and the quality of tax service simultaneously have positive effect towards motivation in paying income tax.
\end{abstract}

Keywords: Tax Knowledge, The Quality of Tax Service, Motivation In Paying Income Tax.

\section{PENDAHULUAN}

Pajak merupakan salah satu sumber penerimaan negara yang sangat penting karena pajak digunakan untuk melaksanakan dan meningkatkan pembangunan bagi seluruh rakyat Indonesia, serta memiliki tujuan untuk meningkatkan kemakmuran, kualitas dan kesejahteraan dalam suatu negara. Oleh karena itu, pajak harus dikelola secara seksama dengan meningkatkan peran seluruh masyarakat dan dari aparat perpajakan yang ada. Hal ini dapat dilihat dari perekonomian Indonesia yang tertuang dalam APBN 2017. Dalam APBN 2017 diperlihatkan bahwa negara Indonesia memiliki pendapatan sebesar 85,6 persen yang berasal dari pajak (kemenkeu.go.id). Untuk meningkatkan pendapatan negara yang berasal dari pajak, Direktorat Jenderal Pajak melakukan perubahan sistem pajak agar sistem perpajakan dapat mengalami penyederhanaan dalam banyak hal serta memudahkan wajib pajak. Pada awal tahun 1983, pemerintah Indonesia mulai menggunakan Self Assestment System, dimana dalam sistem ini diberikan kepercayaan kepada masyarakat yang wajib membayar pajak untuk memperhitungkan, membayar dan melapor jumlah pajak yang terutang berdasarkan undang-undang.

Umumnya masyarakat masih belum memahami dan menyadari dengan baik tentang hak dan kewajibannya dalam perpajakan, dan masyarakat masih kurang percaya terhadap keberadaan pajak karena dipandang sebagai hal yang memberatkan, pembayarannya sering mengalami kesulitan, tidak mengertinya masyarakat mengenai apa dan bagaimana pajak dan sulitnya menghitung dan melaporkannya (Susanto, 2012). Dari hal tersebut, dapat dikatakan bahwa masih banyak masyarakat Indonesia yang belum memahami tentang betapa pentingnya pajak karena masih dianggap hal yang memberatkan bukan bermanfaat karena tidak dapat merasakan secara langsung keuntungan dari membayar pajak.

Karena kurangnya pemahaman dan kesadaran mengenai betapa pentingnya membayar pajak dan manfaat pajak bagi negara dan dirinya sebagai penduduk negara tersebut, juga dilihat dari definisi pajak adalah iuran wajib berdasarkan undang-undang yang berlaku atau peralihan kekayaan dari sektor swasta kepada publik dan tidak mendapat manfaat yang langsung dapat dirasakan dan digunakan untuk membiayai kebutuhan negara (Soemitro, 
2012) seringkali membuat masyarakat hanya membayar pajak karena terpaksa sebab dianggap jika tidak membayar pajak akan dipandang melanggar peraturan perpajakan dan pada akhirnya akan dikenakan sanksi - sanksi yang ada.

Motivasi adalah dorongan kehendak yang menyebabkan individu untuk melakukan suatu perbuatan demi tujuan tertentu. Hal ini menggerakkan seseorang untuk mencapai sesuatu karena kebutuhan, keinginan dan tujuan. Oleh karena itu, perbuatan seseorang karena berdasarkan motivasi tertentu mengandung hal sesuai dengan motivasi yang mendasarinya dikutip dari Daulat (2014:3). Juga menurut Nila (2011:5) "Motivasi wajib pajak dalam membayar pajak akan meningkat bilamana dalam masyarakat muncul persepsi positif terhadap pajak". Jadi dapat diambil kesimpulan bahwa adanya motivasi dalam wajib pajak berarti wajib pajak tersebut telah memiliki persepsi yang positif akan pajak. Melihat dari pentingnya motivasi tersebut, maka penulis ingin mencari hal-hal yang mempengaruhi adanya motivasi tersebut. Motivasi dipengaruhi oleh 2 faktor yaitu faktor dari dalam dan dari luar (Prasetya, 2014). Faktor dari dalam (internal) merupakan faktor yang menyangkut dari dalam diri seseorang sedangkan dari luar (eksternal) berasal dari luar diri seseorang. Penelitian ini peneliti memilih 2 faktor yang dianggap sebagai faktor internal dan eksternal yang mempengaruhi motivasi dalam membayar pajak yaitu Pengetahuan Perpajakan (internal) dan Kualitas Pelayanan Pajak (eksternal).

Faktor yang pertama adalah pengetahuan perpajakan yang dimiliki oleh wajib pajak. Penelitian Istanto (2010:77) berkata apabila individu mempunyai pengetahuan pajak yang baik yaitu mengenai bagaimana pentingnya pajak yang digunakan negara untuk membiayai keperluan suatu negara dengan rakyat yang ada di dalamnya, maka semakin tinggi tingkat pengetahuan seseorang, akan memperbesar motivasinya untuk menyetor pajak terutang. Mukasa (2013) juga berpendapat bahwa pengetahuan tentang perpajakan dapat mempengaruhi keadilan pajak yang dirasakan oleh para pembayar pajak. Bagi pembayar pajak untuk secara akurat menghitung kewajiban pajaknya. Faktor kedua adalah kualitas pelayanan pajak yang berasal dari aparat perpajakan. Kualitas Faktor kedua kualitas pelayanan pajak menurut Kotler (2012:83) adalah "serangkaian perbuatan nyata yang dilakukan untuk mewujudkan pemberian layanan yang terbaik bagi wajib pajak". Pada penelitian Caroko (2015:3) dikatakan jika kantor pelayanan pajak senantiasa memberikan interaksi dan pelayanan yang sangat baik akan memberikan hal-hal positif untuk dipandang dari pajak itu sendiri. Nurhayati Nunung, Halimatusadiah Elly, Diamonalisa (2015:3) juga menyatakan bahwa peningkatan kualitas layanan petugas pajak diharapkan dapat meningkatkan kepuasan pembayar pajak sebagai pelanggan, yang dapat mengarah pada peningkatan pembayaran pajak.

\section{TINJAUAN PUSTAKA}

Pajak. Menurut P.J.A. Andriani (2009) pajak adalah sesuatu yang dipungut dari masyarakat kepada negara yang dapat untuk dipaksakan serta akan terhutang bagi yang wajib membayarnya yang sesuai dengan peraturan undang-undang dengan tidak dapat memperoleh imbalan yang langsung bisa dipakai dalam pendanaan yang diperlukan negara.

Pengetahuan Perpajakan. Pengetahuan adalah informasi atau maklumat yang diketahui atau disadari oleh seseorang (Meliono, 2007). Menurut Carolina (2009:7) pengetahuan perpajakan merupakan info pajak yaitu yang memadai dan dipakai sebagai dasar untuk bertindak dan untuk menempuh arah atau strategi tertentu sehubungan dengan pelaksanaan kepentingan dibidang perpajakan oleh para wajib pajak.

Kualitas Pelayanan Pajak. Menurut Tjiptono (2004:59) kualitas pelayanan adalah tingkat keunggulan dan pengendalian yang diharapkan untuk memenuhi keinginan pelanggan. Apabila pelayanan yang diterima dapat memenuhi ekspektasi yang diinginkan, maka dianggap baik. Jika tidak memenuhi harapan, maka dianggap below expectation atau buruk. 
Motivasi Wajib Pajak. Menurut Weiner (2003) motivasi merupakan dorongan dari dalam diri yang membuat kita bertindak, mendorong untuk mencapai tujuan tertentu, dan membuat seseorang tetap melakukan kegiatan tertentu. Menurut Nila (2011:5) jika terdapat pandangan baik dari perpajakan dalam masyarakat, akan menambah motivasi setiap wajib pajak agar membayar pajak.

Pajak Penghasilan. Menurut Suandy (2011:36) "Pajak Penghasilan adalah pajak yang dikenakan terhadap penghasilan, dapat dikenakan secara berkala dan berulang-ulang dalam jangka waktu tertentu baik masa pajak maupun tahun pajak".

Pengaruh Pengetahuan Perpajakan Terhadap Motivasi Dalam Membayar Pajak Penghasilan. Pengetahuan pajak adalah berbagai hal yang perlu disadari wajib pajak sebagai dasar untuk mengetahui hak dan kewajibannya dalam pepajakan dan sebagai pedoman untuk mencegah terjadinya kecurangan dalam perpajakan. Tingkat pengetahuan seseorang dipengaruhi oleh beberapa faktor yaitu pendidikan, media dan keterpaparan informasi. Tingginya tingkat pengetahuan wajib pajak akan perpajakan akan mempengaruhi sudut pandang dan cara berfikir. Apabila wajib pajak memiliki pengetahuan yang luas tentang halhal perpajakan maka akan mempengaruhi persepsinya tentang pajak menjadi lebih baik dan akhirnya akan berpengaruh terhadap motivasi seseorang dalam membayar pajak. Hasil penelitian ini didukung dengan penelitian sebelumnya yang dilakukan oleh Istanto (2010) dimana terdapat hasil yang juga membuktikan bahwa pengetahuan tentang pajak memiliki pengaruh positif dan signifikan terhadap motivasi dalam membayar pajak. Dari uraian tersebut maka hipotesis yang dirumuskan:

$H_{1}$ : Pengetahuan perpajakan berpengaruh terhadap meningkatnya motivasi dalam membayar pajak penghasilan WPOP Kec. Wanea Kota Manado.

Pengaruh Kualitas Pelayanan Pajak Terhadap Motivasi Dalam Membayar Pajak Penghasilan. Kualitas pelayanan pajak adalah hal yang ditempuh atau dijalankan untuk mewujudkan pemberian layanan yang terbaik bagi wajib pajak. Jika kualitas layanan yang berasal dari aparat perpajakan dalam melayani segala hal berhubungan dengan kepentingan wajib pajak terlihat sangat berkualitas dan baik maka dapat membuat tingkat motivasi masyarakat untuk membayar pajak lebih tinggi. Hasil ini konsisten dengan penelitian oleh Caroko, Susilo dan Zahroh (2015) yang memiliki hasil bahwa pengaruh pelayanan aparat pajak memiliki dampak positif terhadap motivasi wajib pajak orang pribadi dalam membayar pajak penghasilan. Dari uraian diatas maka hipotesis yang dirumuskan:

$\mathrm{H}_{2}$ : Kualitas Pelayanan Pajak berpengaruh terhadap meningkatnya motivasi dalam membayar pajak penghasilan WPOP Kec. Wanea Kota Manado.

Pengaruh Pengetahuan Perpajakan dan Kualitas Pelayanan Pajak Terhadap Motivasi Dalam Membayar Pajak Penghasilan. Dengan adanya pengetahuan perpajakan yang luas, wajib pajak tentunya akan lebih mengetahui dan memahami akan betapa pentingnya fungsi pajak bagi negara dimana kita hidup. Kualitas pelayanan adalah upaya pemenuhan kebutuhan dan keinginan pihak yang menerima layanan serta ketepatan penyampaiannya dalam mengimbangi harapan konsumen. Jadi apabila tercipta pelayanan perpajakan yang sangat berkualitas akan sangat membantu dalam mendorong motivasi dalam membayar pajak penghasilan. Dari uraian tersebut maka hipotesis yang dirumuskan:

$H_{3}$ :Pengetahuan perpajakan dan kualitas pelayanan pajak secara simultan berpengaruh terhadap motivasi dalam membayar pajak penghasilan WPOP Kec. Wanea Kota Manado. 


\section{METODE PENELITIAN}

Jenis dan Sumber Data. Jenis penelitian adalah penelitian kuantitatif. Dilihat dari hubungan antar variabel, maka ini merupakan penelitian correlational, untuk menentukan apakah terdapat hubungan antara variabel independen yaitu pengetahuan perpajakan $\left(\mathrm{X}_{1}\right)$, kualitas pelayanan pajak $\left(\mathrm{X}_{2}\right)$ terhadap variabel dependen yaitu motivasi dalam membayar pajak penghasilan (Y). Sumber data yang digunakan dalam penelitian ini adalah data primer yang pengambilannya secara langsung dari responden tanpa adanya perantara, yaitu jawaban dari kuesioner yang dibagikan.

Sampel dan Teknik Pengambilan Sampel. Populasi penelitian ini adalah seluruh WPOP yang bertempat tinggal di wilayah Kecamatan Wanea Kota Manado. Sedangkan sampel yang diambil adalah 40 WPOP yang bertempat tinggal di wilayah Kecamatan Wanea Kota Manado. Teknik pengambilan sampel yang digunakan adalah nonprobability sampling, dengan menggunakan purposive sampling, yaitu teknik pengambilan sampel berdasarkan kriteria yang telah ditentukan (Kuncoro:2014). Berdasarkan teknik pengambilan sampel tersebut, maka kriteria yang digunakan dalam penelitian ini adalah sebagai berikut: (1) responden merupakan wajib pajak orang pribadi yang memiliki usaha sendiri/wirausaha; dan (2) responden memiliki pendapatan di atas PTKP.

Metode Analisis Data. Metode analisis data dalam penelitian ini adalah analisis regresi linear berganda dengan bantuan program SPSS versi 23. Analisis linear berganda adalah analisis yang dipakai untuk mengetahui pengaruh beberapa variabel independen (X) terhadap variabel dependen (Y).

\section{HASIL ANALISIS DAN PEMBAHASAN \\ 4.1. Hasil Analisis}

Uji Kualitas Data

Uji Validitas. Sebuah kuesioner dapat dinyatakan valid jika nilai $r_{\text {hitung }}>r_{\text {tabel }}$ dan atau nilai sig < 0,05 maka item pertanyaan tersebut dianggap valid (Thoifah, 2015: 111).

Tabel 1. Hasil Uji Validitas Pengetahuan Perpajakan $\left(\mathbf{X}_{1}\right)$

\begin{tabular}{cccc}
\hline No. Pertanyaan & r hitung & r tabel & Keterangan \\
\hline 1 & 0,580 & 0,312 & Valid \\
2 & 0,735 & 0,312 & Valid \\
3 & 0,741 & 0,312 & Valid \\
4 & 0,656 & 0,312 & Valid \\
5 & 0,844 & 0,312 & Valid \\
6 & 0,777 & 0,312 & Valid \\
7 & 0,729 & 0,312 & Valid \\
\hline
\end{tabular}

Sumber: Data olahan SPSS (2018

Tabel 2. Hasil Uji Validitas Kualitas Pelayanan Pajak $\left(\mathbf{X}_{2}\right)$

\begin{tabular}{cccc}
\hline No. Pertanyaan & r hitung & r tabel & Keterangan \\
\hline 1 & 0,336 & 0,312 & Valid \\
2 & 0,592 & 0,312 & Valid \\
3 & 0,469 & 0,312 & Valid \\
4 & 0,656 & 0,312 & Valid \\
5 & 0,720 & 0,312 & Valid \\
6 & 0,701 & 0,312 & Valid \\
7 & 0,692 & 0,312 & Valid \\
8 & 0,602 & 0,312 & Valid \\
9 & 0,633 & 0,312 & Valid \\
\hline
\end{tabular}

Sumber: Data olahan SPSS (2018) 
Tabel 3. Hasil Uji Validitas Motivasi Dalam Membayar Pajak Penghasilan (Y)

\begin{tabular}{cccc}
\hline No. Pertanyaan & r hitung & r tabel & Keterangan \\
\hline 1 & 0,470 & 0,312 & Valid \\
2 & 0,474 & 0,312 & Valid \\
3 & 0,394 & 0,312 & Valid \\
4 & 0,394 & 0,312 & Valid \\
5 & 0,532 & 0,312 & Valid \\
6 & 0,431 & 0,312 & Valid \\
7 & 0,347 & 0,312 & Valid \\
8 & 0,533 & 0,312 & Valid \\
\hline
\end{tabular}

Sumber: Data olahan SPSS (2018)

Dapat dilihat diatas, uji validitas menunjukkan bahwa semua pertanyaan untuk kedua variabel independen dan variabel dependen memiliki kriteria valid dengan nilai $r_{\text {hitung }}$ lebih besar dari $r_{\text {tabel }}$ sehingga semua pertanyaan tersebut dinyatakan valid atau dapat dipakai untuk mengukur masing-masing variabel.

Uji Reliabilitas. Uji ini dipakai dalam memastikan apakah kuesioner yang dipakai reliabel atau tidak juga konsistensi dan stabilitas kuesioner jika digunakan dari waktu ke waktu (Ghozali, 2011). Uji reliabilitas dilakukan dengan cara menghitung koefisien cronbach's alpha > 0,60 maka dapat disimpulkan bahwa instrumen penelitian tersebut reliabel.

Tabel 4. Hasil Uji Reliabilitas

\begin{tabular}{lcc}
\hline \multicolumn{1}{c}{ Variabel } & Cronbach's Alpha & Keterangan \\
\hline Pengetahuan Perpajakan & 0,844 & Reliabel \\
Kualitas Pelayanan Pajak & 0,786 & Reliabel \\
Motivasi Dalam Membayar Pajak Penghasilan & 0,432 & Reliabel \\
\hline
\end{tabular}

Sumber : Data olahan SPSS(2018)

Tabel 4 menunjukkan semua pertanyaan dalam setiap variabel memiliki nilai koefisien cronbach's alpha > 0,60, maka dapat disimpulkan bahwa seluruh pertanyaan dalam kuesioner reliabel.

\section{Uji Asumsi Klasik}

Uji Normalitas. Uji normalitas ini menggunakan rumus Kolmogorov-Smirnov. Dasar pengambilan keputusan untuk uji normalitas yaitu jika nilai signifikansi lebih besar dari 0,05 maka data tersebut berdistribusi normal dan sebaliknya.

Tabel 5. Hasil Uji Normalitas

One-Sample Kolmogorov-Smirnov Test

\begin{tabular}{llr} 
& & Unstandardized Residual \\
\hline Normal Parameters & & 40 \\
& Mean & .0000000 \\
Most Extreme Differences & Std. Deviation & 1.93074831 \\
& Absolute & .048 \\
& Positive & .048 \\
Test Statistic & Negative & -.043 \\
Asymp. Sig. (2-tailed) & & .048 \\
\hline Sumber : Data & & $0.200^{\text {c,d }}$ \\
\hline
\end{tabular}

Sumber : Data olahan SPSS(2018) 
Tabel 5 menunjukkan nilai signifikansi >0,05. Hal ini dibuktikan dengan nilai asymp. Sig $0,200>0,05$, menunjukkan bahwa data telah berdistribusi secara normal.

Uji Multikolinearitas. Uji ini dilakukan untuk mendeteksi gejala korelasi antara variabel independen yang satu dengan variabel independen yang lain. Dengan melihat nilai tolerance dan nilai Variance Inflation Factors. Jika nilai tolerance $>0,10$ dan VIF $<10$ maka dinyatakan tidak ada korelasi sempurna antara variabel independen (Ghozali, 2011).

Tabel 6. Hasil Uji Multikolinearitas

\begin{tabular}{llcr}
\hline & & \multicolumn{2}{c}{ Collinearity Statistics } \\
\cline { 3 - 4 } Model & & \multicolumn{2}{c}{ Tolerance } \\
\hline 1 & (Constant) & .999 & 1.001 \\
& Pengetahuan Perpajakan & .999 & 1.001 \\
\hline
\end{tabular}

Sumber : Data olahan SPSS(2018)

Tabel 6 menunjukan nilai tolerance setiap variabel independen $>0,10$ dan nilai VIF setiap variabel independen $<10$, sehingga penelitian ini tidak mengalami multikolinearitas.

Uji Heteroskedastisitas. Uji heteroskedastisitas dalam penelitian ini menggunakan uji Glesjer. Apabila koefisien signifikansi lebih besar dari tingkat signifikansi yang ditetapkan, maka dapat disimpulkan tidak terjadi heteroskedastisitas (Thoifah, 2015: 222).

Tabel 7. Hasil Uji Heteroskedastisitas dengan Uji Glesjer

\begin{tabular}{lr} 
Model & Sig. \\
\hline 1 (Constant) & 0.167 \\
Pengetahuan Perpajakan & 0.543 \\
Kualitas Pelayanan Pajak & 0.853 \\
\hline
\end{tabular}

Sumber : Data olahan SPSS(2018)

Tabel 7 menunjukkan signifikansi variabel pengetahuan perpajakan 0,543 dan variabel kualitas pelayanan pajak 0,853 menunjukkan signifikansi > 0,05. Maka dapat disimpulkan bahwa tidak terjadi heteroskedastisitas pada model regresi.

\section{Analisis Regresi Linear Berganda}

Tabel 8. Hasil Analisis Regresi

Coefficients $^{\mathrm{a}}$

\begin{tabular}{|c|c|c|c|c|c|c|}
\hline \multirow[b]{2}{*}{ Model } & & \multicolumn{2}{|c|}{ Unstandardized Coefficients } & $\begin{array}{l}\text { Standardized } \\
\text { Coefficients }\end{array}$ & \multirow[b]{2}{*}{$\mathrm{t}$} & \multirow[b]{2}{*}{ Sig. } \\
\hline & & $\mathrm{B}$ & Std. Error & Beta & & \\
\hline 1 & (Constant) & 25.209 & 2.351 & & 10.721 & 0.000 \\
\hline & $\begin{array}{l}\text { Pengetahuan } \\
\text { Perpajakan }\end{array}$ & .205 & .056 & .427 & 3.630 & 0.001 \\
\hline & $\begin{array}{l}\text { Kualitas } \\
\text { Pelayanan Pajak }\end{array}$ & .197 & .043 & .541 & 4.594 & 0.000 \\
\hline
\end{tabular}

a. Dependent Variable: Motivasi Dalam Membayar Pajak Penghasilan

Sumber : Data olahan SPSS(2018) 
Berdasarkan tabel 8 diperoleh persamaan regresi berganda sebagai berikut:

$$
Y=25,209+0,205 X_{1}+0,197 X_{2}+\varepsilon \ldots
$$

Dengan interpretasi bahwa:

1. Nilai konstanta $(\alpha)$ sebesar 25,209 bernilai positif artinya variabel motivasi dalam membayar pajak penghasilan mempunyai hubungan positif dan searah dengan pengetahuan perpajakan (X1) dan kualitas pelayanan pajak (X2).

2. Variabel pengetahuan perpajakan (X1) memiliki nilai koefisien regresi $\left(\beta_{1}\right)$ sebesar 0,205 dan bernilai positif, memperlihatkan bahwa pengetahuan perpajakan berpengaruh positif terhadap motivasi dalam membayar pajak penghasilan.

3. Variabel kualitas pelayanan pajak (X2) mempunyai nilai koefisien regresi $\left(\beta_{2}\right)$ sebesar 0,197 dan memiliki nilai positif, menunjukkan kualitas pelayanan pajak berpengaruh positif terhadap motivasi dalam membayar pajak penghasilan.

Uji Simultan (Uji F). Uji F digunakan untuk mengetahui apakah secara bersama-sama (simultan) variabel independen mempunyai pengaruh nyata atau tidak terhadap variabel dependen.

Tabel 9. Hasil Uji Simultan (Uji F)

\begin{tabular}{llrrrrr}
\hline \multicolumn{7}{c}{ ANOVA $^{\mathrm{a}}$} \\
\hline Model & & Sum of Squares & \multicolumn{1}{c}{ df } & Mean Square & F & \multicolumn{1}{c}{ Sig. } \\
\hline 1 & Regression & 30.990 & 2 & 15.495 & 17.581 & $0.000^{\mathrm{b}}$ \\
& Residual & 32.610 & 37 & .881 & & \\
& Total & 63.600 & 39 & & & \\
\hline
\end{tabular}

a. Dependent Variable: Motivasi Dalam Membayar Pajak Penghasilan

b. Predictors: (Constant), Kualitas Pelayanan Pajak, Pengetahuan Perpajakan

Sumber : Data olahan SPSS(2018)

Tingkat signifikansi penelitian ini adalah 0,05. Adapun metode penentuan $\mathrm{F}_{\text {tabel }}$ menggunakan ketentuan $\mathrm{N} 1=\mathrm{k}-1$ dan $\mathrm{N} 2=\mathrm{n}-\mathrm{k}$, sehingga didapat nilai $\mathrm{F}_{\text {tabel }}$ sebesar 3,25. Tabel 9 menunjukkan hasil analisis menggunakan $F_{\text {hitung }}=17,581>F_{\text {tabel }}=3,25$ dengan signifikansi $0,000<0,05$, maka dapat disimpulkan variabel pengetahuan perpajakan dan kualitas pelayanan pajak secara simultan berpengaruh signifikan terhadap motivasi dalam membayar pajak penghasilan.

Uji Parsial (uji t). Uji t digunakan untuk menguji apakah hipotesis yang diajukan dalam penelitian ini diterima atau tidak dengan mengetahui bagaimana pengaruh variabel independen secara individual terhadap variabel dependen.

Tabel 10. Hasil Uji Parsial (uji t)

Coefficients $^{\mathrm{a}}$

\begin{tabular}{|c|c|c|c|c|c|}
\hline \multirow[b]{2}{*}{ Model } & \multicolumn{2}{|c|}{ Unstandardized Coefficients } & $\begin{array}{l}\text { Standardized } \\
\text { Coefficients }\end{array}$ & \multirow[b]{2}{*}{$\mathrm{t}$} & \multirow[b]{2}{*}{ Sig. } \\
\hline & $\mathrm{B}$ & Std. Error & Beta & & \\
\hline $1 \quad$ (Constant) & 25.209 & 2.351 & & 10.721 & 0.000 \\
\hline $\begin{array}{l}\text { Pengetahuan } \\
\text { Perpajakan }\end{array}$ & .205 & .056 & 427 & 3.630 & 0.001 \\
\hline $\begin{array}{l}\text { Kualitas Pelayanan } \\
\text { Pajak }\end{array}$ & .197 & .043 & .541 & 4.594 & 0.000 \\
\hline
\end{tabular}

a. Dependent Variable: Motivasi Dalam Membayar Pajak Penghasilan

Sumber : Data olahan SPSS (2018) 
Metode dalam penentuan $t_{\text {tabel }}$ menggunakan $\mathrm{df}=\mathrm{n}-\mathrm{k}-1(\mathrm{df}=40-2-1=37)$, sehingga didapat nilai $t_{\text {tabel }}$ sebesar 1,687. Dilihat dari Tabel 10 variabel pengetahuan perpajakan menunjukkan nilai $t_{\text {hitung }}$ sebesar 3,630 $>\mathrm{t}_{\text {tabel }}$ sebesar 1,687 dengan signifikansi sebesar 0,001 $<0,05$. Hal ini menunjukkan bahwa secara parsial pengetahuan perpajakan memiliki pengaruh signifikan terhadap motivasi dalam membayar pajak penghasilan. Jadi, hipotesis $\mathrm{Ha}_{1}$ diterima dan $\mathrm{Ho}_{1}$ ditolak. Variabel kualitas pelayanan pajak menunjukkan nilai $t_{\text {hitung }}$ sebesar 4,594 $>t_{\text {tabel }}$ sebesar 1,687 dengan signifikansi sebesar $0,000<0,05$. Hal ini menunjukkan secara parsial kualitas pelayanan pajak memiliki pengaruh signifikan terhadap motivasi dalam membayar pajak penghasilan. Jadi, hipotesis $\mathrm{Ha}_{2}$ diterima dan $\mathrm{Ho}_{2}$ ditolak.

Koefisien Determinasi. Menurut Ghozali (2013: 197), koefisien determinasi $\left(\mathrm{R}^{2}\right)$ mengukur seberapa jauh kemampuan variabel independen dalam menerangkan variasi variabel dependen.

Tabel 11. Hasil Koefisien Determinasi

\begin{tabular}{ccccc}
\hline & \multicolumn{3}{c}{ Model Summary $^{\mathrm{b}}$} \\
\hline Model & $\mathrm{R}$ & R Square & Adjusted R Square & Std. Error of the Estimate \\
\hline 1 & $.698^{\mathrm{a}}$ & .487 & .460 & 0.939 \\
\hline
\end{tabular}

a. Predictors: (Constant), Kualitas Pelayanan Pajak, Pengetahuan Perpajakan

b. Dependent Variable: Motivasi Dalam Membayar Pajak Penghasilan

Sumber : Data olahan SPSS (2018)

Berdasarkan Tabel 11 besarnya R Square adalah 0,487 nilai ini menunjukkan, 48,7\% variasi motivasi dalam membayar pajak penghasilan yang dalam hal ini wajib pajak orang pribadi di Kecamatan Wanea Kota Manado dapat dijelaskan oleh kedua variabel independen yaitu pengetahuan perpajakan (X1) dan kualitas pelayanan pajak (X2), sedangkan sisanya 51,3\% dijelaskan oleh variabel lain yang tidak diteliti dalam penelitian ini.

\subsection{Pembahasan}

Hasil pengujian hipotesis pertama menunjukkan, semakin besar pengetahuan perpajakan yang dimiliki wajib pajak, tinggi pula peningkatan motivasi dalam membayar pajak penghasilan WPOP di Kec. Wanea Kota Manado. Hasil pengujian hipotesis kedua menunjukkan, semakin berkualitas pelayanan yang diberikan aparat perpajakan, akan mendorong peningkatan motivasi dalam membayar pajak penghasilan WPOP di Kec. Wanea Kota Manado. Hasil pengujian hipotesis ketiga menunjukkan bahwa semakin besar pengetahuan perpajakan yang dimiliki wajib pajak dan semakin tinggi kualitas pelayanan yang diberikan aparat perpajakan, maka semakin tinggi pula peningkatan motivasi dalam membayar pajak penghasilan WPOP di Kec. Wanea Kota Manado.

\section{KESIMPULAN DAN SARAN}

\subsection{Kesimpulan}

Berdasarkan hasil penelitian dan pembahasan sebelumnya, maka disimpulkan bahwa:

1. Pengetahuan perpajakan (X1) memiliki pengaruh positif dan signifikan terhadap motivasi dalam membayar pajak penghasilan (Y). Hal ini menunjukkan bahwa semakin tinggi pengetahuan perpajakan yang dimiliki wp orang pribadi dapat memperbesar motivasi wpop dalam membayar pajak penghasilan. Dengan demikian, hipotesis pertama diterima.

2. Kualitas pelayanan pajak (X2) berpengaruh positif dan signifikan terhadap motivasi dalam membayar pajak penghasilan (Y). Hal ini menunjukkan bahwa jika kualitas pelayanan pajak yang diberikan baik maka akan berpengaruh positif terhadap motivasi wpop dalam membayar pajak penghasilan. Dengan demikian, hipotesis kedua diterima. 
3. Variabel pengetahuan perpajakan dan kualitas pelayanan pajak secara simultan berpengaruh signifikan terhadap motivasi dalam membayar pajak penghasilan. Dengan demikian dapat disimpulkan bahwa pengetahuan perpajakan dan kualitas pelayanan pajak memiliki pengaruh signifikan dalam meningkatkan motivasi dalam membayar pajak penghasilan. Sehingga hipotesis ketiga diterima.

\subsection{Saran}

Bagi instansi, untuk instansi-instansi khususnya yang bergerak dalam bidang perpajakan agar dapat lebih bekerja sama dan tidak mempersulit mahasiswa yang ingin melakukan penelitian, karena dengan adanya kerja sama yang baik, maka kedua pihak dapat saling menguntungkan. Mahasiswa dapat memperluas pengetahuan mengenai perpajakan dan memilik persepsi yang baik mengenai cara kerja instansi tersebut karena dalam hal ini instansi yang bersangkutan telah mendukung pendidikan melalui melancarkan jalannya penelitan. Selain itu melalui mahasiswa yang melakukan penelitian instansi dapat membagikan informasi-informasi yang berguna dan dapat disebarkan ke pihak lain agar lebih diketahui dan bermanfaat. Kiranya juga kualitas pelayanan dapat lebih ditingkatkan untuk mendorong wajib pajak agar lebih memperhatikan hak dan kewajibannya dalam perpajakan.

Bagi penelitian berikutnya, bagi peneliti yang selanjutnya ingin melakukan penelitian sejenis dengan yang dilakukan oleh penulis. Sebaiknya berikutnya melakukan pembagian kuesioner di waktu yang tepat jangan pada jam sibuk, usahakan kuesioner dibagikan disaat responden benar-benar memiliki waktu untuk mengisi kuesioner. Diharapkan pula agar peneliti selanjutnya dapat memperbanyak jumlah sampel penelitian serta memilih wilayah penelitian yang lebih luas, dan menambah beberapa variabel yang belum diteliti pada penelitian ini.

\section{DAFTAR PUSTAKA}

Caroko, Bayu. Susilo, Heru. Z.A, Zahroh. 2015. "Pengaruh Pengetahuan Perpajakan,Kualitas Pelayanan Pajak Dan Sanksi Pajak Terhadap Motivasi Wajib Pajak Orang Pribadi Dalam Membayar Pajak". Skripsi Program Studi Perpajakan, Jurusan Administrasi Bisnis, Fakultas Ilmu Administrasi Universitas Brawijaya, Indonesia.

Carolina, Veronica. (2009). Pengetahuan Pajak. Jakarta: SalembaEmpat.

Freddy, Daulat. 2014. "Pengaruh Pendidikan Dan Sanksi Perpajakan Terhadap Motivasi Wajib Pajak Dalam Memenuhi Kewajiban Perpajakan”. Skripsi Fakultas Ekonomi Universitas Esa Unggul, Jakarta.

Ghozali, Imam. 2013. Aplikasi Analisis Multivariat dengan Program IBM SPSS 21. Edisi Ketujuh. Universitas Dipenogoro. Semarang.

Istanto, Fery. 2010. “Analisis Pengaruh Pengetahuan Tentang Pajak, Kualitas Pelayanan Pajak, Ketegasan Sanksi Perpajakan dan Tingkat Pendidikan Terhadap Motivasi Wajib Pajak Dalam Membayar Pajak". Skripsi Fakultas Ekonomi dan Ilmu Sosial Universitas Islam Negeri Syarif Hidayatullah Jakarta.

Kementrian Keuangan Republik Indonesia. Pendapatan Negara. https://www.kemenkeu.go.id/apbn2017

Kotler, Philip. 2012. Manajemen Pemasaran, Edisi Millenium, Jilid 2, PT Prenhallindo, Jakarta

Kuncoro, Mudrajad. 2014. Metode Riset untuk Bisnis \& Ekonomi. Edisi Keempat. Erlangga. Jakarta.

Meliono. Kamus Besar Bahasa Indonesia, Penerbit Balai Pustaka, Jakarta: 2007 
Mukasa, J. (2013) Tax Knowledge, Perceived Tax Fairness and Tax Compliance in Uganda. Master of Science, Makerere University, Kampala.

Nila, Yulianawati. 2011. "Faktor-Faktor yang Mempengaruhi Kemauan untuk Membayar Pajak Wajib Pajak Orang Pribadi yang Melakukan Pekerjaan Bebas “. Prodi Akuntansi, Fakultas Ekonomi, Universitas Katolik Widya Mandala Madiun.

Nurhayati, Nunung. Halimatusadiah, Elly. Diamonalisa. (2015). Influence of tax officer service quality and knowledge of tax on individual taxpayer compliance in tax office (kpp) Bojonagara Bandung.

P.J.A Andriani. 2009. Akuntansi Pajak .Jakarta . Penerbit : Salemba Empat

Prasetya, Ferilian. 2014. Faktor-Faktor yang Mempengaruhi Motivasi. (http:// prasetyaferilian.blogspot.com).

Suandy Erly. (2011). Perpajakan. Edisi Kedua. Jakarta: Salemba Empat.

Susanto, Herry. 2012. "Juara II Lomba Artikel Pajak Nasional Direktorat Jenderal Pajak". Melalui www.pajak.go.id. Diakses 28 November 2016, 22:00 WIB

Thoifah, I'anatut. 2015. Statistika Pendidikan dan Metode Penelitian Kuantitatif. Jawat Timur: Madani.

Tjiptono, Fandy. 2004. Manajemen Jasa, Edisi Pertama, Yogyakarta, Andi Offset.

Weiner, I. 2003. Handbook Of Psychology. Vol 7, Education Psychology. 